\title{
ASYLUM INTERVIEW AS A FORK ON THE ROAD - FROM ASYLUM SEEKER TO IRREGULAR MIGRANT
}

\author{
Katri Johanna Gadd ${ }^{1}, \&$ Laura Sofia Lehtikunnas ${ }^{2}$ \\ ${ }^{1}$ Department of Geography and Geology, University of Turku (Finland) \\ ${ }^{2}$ Department of Law, University of Turku (Finland)
}

\begin{abstract}
Many asylum seekers have encountered various types of violence in their lives including physical and verbal harm, but also emotional violence. This paper evaluates yet another type of violence, namely epistemic violence, which asylum seekers may encounter when they arrive to a country seeking asylum. Epistemic violence is a failure of hearers to understand and acknowledge the speech of speakers in linguistic exchanges causing a negative impact on the speaker. Thus, epistemic violence is indirect and non-physical, yet it might have extremely severe legal and psychological consequences, such as a negative decision on an asylum request and the trauma caused by the decision and the situation in which person encounters the fork on the road: "Should I stay in Finland, or should I go?".

In 2015, Finland received an eightfold number of asylum applications compared with the previous years. Finnish authorities were not well prepared for the increase and in 2016 laws and regulations regarding immigration and legal aid were amended. According to the amended law, the legal assistance in the asylum interview is in practice no longer possible unless there are particularly serious reasons.

In this paper we report findings from interviews with 70 former asylum seekers regarding their experiences of their asylum interviews. We illustrate that many former asylum seekers did not experience to have been able to tell their story in such a way that their realities would have been understood and now they are irregular migrants.

Irregular migration is a timely phenomenon. Furthermore, it is highly multidisciplinary phenomenon requiring a holistic evaluation and discussion gathering academics from various disciplines including (but not being limited to) psychology, geography, sociology and law.

Epistemic violence needs to be avoided as much as possible in European immigration and social policies as it might increase irregular migration. Moreover, most importantly, it increases unnecessary agony and psychological stress for individual asylum seekers. Epistemic violence, as any other violence, has significant psychological effects through the negotiation of individual's self-esteem on a moment in which many experience to have lost the direction of the life. Consequently, we stress that the decision makers ought to acknowledge the possible side effects of the chosen social policies as those side effects such as an increase in experienced epistemic violence, might have extensive impact on living conditions and the quality of life of people in the society.
\end{abstract}

Keywords: Irregular migrants, asylum seekers, asylum interview, epistemic violence, Finland.

\section{Introduction}

The whole asylum process is about a story. The story needs to be personal, coherent, well-founded, credible and detailed. This story needs to be told in one asylum interview. If a person fails to tell the story in a right way, s/he risks of receiving a negative decision on his/her asylum request and facing the question whether to stay in a country as irregular migrant or to leave the country (Lehtikunnas, 2018). Asylum seekers' personal qualities, the abilities to understand the asylum process and individual perseverance become emphasised in the processes. The asylum seeker needs to be capable to analyse how the interpreters have put the words and to insist on correcting the possible shortcomings or even mistakes. However, as the translation is to a language asylum seekers do not often know, assuring that the translation is correct is challenging. Moreover, it is very difficult to know how the individual story will be understood in the asylum process; how the interpreter translates it and how the interviewer then interprets it. For some asylum seekers trusting fully in authorities is counterintuitive and even impossible. Taking 
into account, moreover, the fact that the asylum seekers are sometimes traumatised, the possibilities for a coherent storytelling might be jeopardised.

In 2015, nearly 33000 people came to Finland to seek asylum (Migri 2018). Finnish authorities were not well prepared to this increase in the amount of asylum seekers (the normal annual amount of new asylum seekers in Finland varies from 3000 to 4000). At European level the absolute number of asylum seekers arriving in Finland in 2015 was not high. However, the relative increase in the asylum applications was, in fact, among the highest in Europe (Jauhiainen, 2017). If the conditions for asylum or subsidiary protection were not fulfilled but the applicant could not return to their home country due to a poor security situation or an environmental disaster, residence permits could be obtained on the basis of humanitarian protection (Aer, 2016, p. 253). In 2016 the conditions for obtaining asylum and other residence permits in Finland were tightened and this possibility was removed from the Finnish law. Moreover, in 2016 restrictions on legal assistance in asylum process were introduced. The legal assistance by private lawyers in the asylum process at the Finnish Immigration Service (Migri) is no longer possible unless the presence of the assistant is necessary for particularly serious reasons such as particularly weak mental or health situation or if the asylum seeker is under 18 years old and in the country without a guardian (Changes on Aliens Act $9 \S$ and the Legal Aid Act). Relatively common depression and anxiety or trauma are not enough to fulfil this condition. Due to the tightening asylum policies of the European Union (EU) and Finland, more people become irregular migrants as not all who get a negative decision to their asylum requests want to leave or feel that they could leave (Düvell, 2011).

\section{Epistemic violence}

Post-colonial researcher and philosopher Gayatri Spivak (1988) raised up the discussion about epistemic violence by questioning if the subaltern, the lowest strata of the urban sub proletariat, has a voice. She used the term epistemic violence in a rather general sense whenever the other had been constructed (Dotson, 2011). Spivak (1988) questioned the possibilities of the marginalised groups to speak, express themselves and for example give a testimony. According to her, epistemic violence is practiced when damaging a given group's ability to speak and be heard (Spivak, 1988). Epistemic violence has been discussed also in psychology, especially in relation to the hermeneutic processes of interpretation of data (see Teo, 2008; 2010), the statements of others.

In the same vein we understand the epistemic violence as a failure of hearers to meet the vulnerabilities of speakers in linguistic exchanges and recognise the speaker as knower (see also Hornsby, 1995; Dotson, 2011; Berenstain, 2016). Here the word 'epistemic' suggests that interpretations in linguistic exchanges are framed as knowledge and 'violence' denotes that this 'knowledge' has potentially a negative impact on the other (Teo, 2010). Practicing epistemic violence (i.e. damaging other person's possibility to speak, express him-/herself and be heard) may be intentional as well as unintentional (Dotson, 2011) and thus, might be difficult to address (Fricker, 2007). Consequently, the violence is indirect and non-physical (Teo, 2010), yet it can potentially have very material consequences.

Possibility for epistemic violence can be seen to be created in dependence relation between the speakers and the audience. The audience needs to understand the speaker's words and understand what the speaker is doing with the words. Therefore, the communication is about the speaker being able not only to express meaningful thoughts but also to be heard leaving the communication ultimately depending on the audience (Hornsby, 1995). Hence, in linguistic communication between the speaker and audience there is a fundamental need for reciprocity. Without the reciprocity the possibilities for epistemic violence are increased.

Lack of knowledge has been presented as one factor creating possibilities for epistemic violence (see e.g. Berging, 2002; Townley, 2006; Dotson, 2011). Refusal or inability, intentional or unintentional, of an audience to communicatively reciprocate a linguistic exchange can follow from the lack of knowledge (Dotson, 2011). The lack of knowledge is not necessarily related to intelligence, but can also be prompted by social positioning causing epistemic difference and inadequate hermeneutical resources (Berenstain, 2016). Epistemic difference here can be understood as a gap between different worldviews caused by differing social situations (e.g. economic, sexual, cultural) producing different understanding of the world (Bergin, 2002, 198). However, lack of knowledge may also be useful if it is used as impetus for study (Townley, 2006). Then, the fact that audience did not understand or was unable to reciprocate in the communication can, at best, lead into a further investigation to increase the understanding.

Dotson $(2011 ; 2014)$ has researched epistemology and epistemic violence especially through different practices of silencing testimony given by oppressed individuals and has highlighted practices that silence, de facto, speakers. One form of epistemic violence as silencing is microinvalidation in power laden communication. It is characterised by communications that exclude, negate, or nullify the psychological thoughts, feelings, or experiential reality of a person (Sue et al. 2007, 274). These communications are violently interpreted in a certain way even though an equally valid alternative interpretation would be possible (Teo, 2008). 


\section{Methods}

Material of this research consists of official documents of international law and the Finnish constitution as background material and in-debt interviews with seventy irregular migrants living in Finland (24 females and 46 males). The interviews were conducted individually or in small groups depending on the preference of the research participants. All the participants have experiences from at least one asylum interview. Moreover, all the research participants have gotten negative decision on their asylum requests. All the interviews were conducted during the years 2018 and 2019.

The empirical data and the background literature were analysed using theory oriented content analysis in order to detect possibilities for epistemic violence in the asylum process and especially in the asylum interview. The material from the interviews was analysed also using thematic content analysis concentrating on the elements of epistemic violence (e.g. mistakes in understanding or in being understood, power imbalance in the interview, nullifying to mention but a few). Those elements were colour coded in order to detect their prevalence in the research participants' experiences of the asylum interviews.

\section{4. "Should I stay or should I go?"}

Asylum seekers' dependence on the hearer, the interviewer, is evident in the asylum interview. Does the interviewer have a common goal with the asylum seeker to make the story as strong as possible? Does the interviewer intend to ask, based on his/her expertise, the right questions benefiting the individual asylum-seeker? Does s/he have hermeneutical resources to understand or does the story remain unintelligible? This relation of dependence is prone to epistemic violence. 42 of our 70 participants had experienced epistemic violence in their asylum interviews.

For the successful interpretations to be formed, there is a great need of reciprocity not only to understand the speaker's words but also in taking the words as they are meant to be taken (Dotson, 2011). Some of the participants of this study explicitly said that they were not happy with the translation made by the interpreter. They told to have corrected various expressions in the minutes. However, in some worst cases the flaws were not detected or the audience, the interviewer was unable to understand the details of the story and the speaker, the asylum seeker was unable to detect the failures in understanding. Failures were only detected when the asylum seeker got a negative decision to his/her asylum request based on misunderstanding in the communication. One participants described this: "Only when I got the first negative decision and read through the papers with my Finnish friend did I realise that no, this wasn't what I meant'. This highlights the difficulty of asylum seekers perceive epistemic violence before the violence actually is materialised as a negative decision. Furthermore, the failures in the linguistic exchange in the interview are extremely difficult to correct afterwards. Changing the wording or expression often leads into a situation in which the creditability of the story is decreased as one of the participants explained: "I made the corrections and appealed. I got second negative decision fast as they [Finnish Immigration Service] said that my story wasn't coherent anymore". Another participant continued: "In my papers there is a line saying that I cannot be granted asylum as I have not been threatened in my home country in 2014 or 2015. I tried to correct this by saying that of course not, because I had already escaped and I was already in a refugee camp. I showed a document from UNHCR. Still negative." In these cases it is evident that the testimony of these individuals have not been heard and there has been severe difficulties in the understanding.

In the negative decisions, it is often claimed that the applicant has been asked to tell everything and there is no legal grounds to give asylum. Nearly all the participants questioned how they would know what is relevant to be told. This problem grew after the amendments in the immigration law in Finland as the legal advice might nowadays be scarce. The lack of advice and knowledge increases the possibility for epistemic violence in the asylum process as it jeopardises the ability of asylum seekers to speak. The lack of knowledge, however, is twofold. On the one hand asylum seekers might not know what to reveal. On the other hand the interviewer might be (intentionally or unintentionally) unable to meet the difference of the other person and thus, understand the linguistic exchange. This ignorance (see Sue et al. 2007) might be caused by the economic, political, sexual, cultural differences between interviewer and the asylum seeker (and the interpreter) producing different understanding of the world (see Bergin, 2002).

In this sense it would be beneficial for the asylum seeker if the interpreter has the same cultural or religious background as the asylum-seeker. However, five participants told to have been afraid of being interfered or judged by the interpreter as the interpreter might have different perception of the situation back home. On the other hand, without having the understanding on the background, it is even more difficult to hear the meaningful aspects of the full story and understand it clearly. Besides these challenges, ten participants told to have used Google Translator in the official asylum interview. These 
aspects create a real danger of intentional as well as unintentional epistemic violence, and the possibility to hinder open communication. Even little misunderstandings and differences in the terminology used in the interview can create dearth in the coherency and credibility of the asylum seeker 's story. Nevertheless, as asylum-seekers' claims are often related to issues strongly based on cultural, political, traditional and religious aspects, the interviewer and interpreter should be able to act and listen objectively without making conclusions and/or interpretations founded on their own experiences and general assumptions.

In order to treat all asylum seekers equally there is "knowledge" called country information of different countries of origin, towards which the stories of individual asylum seekers are mirrored. However, in the cases where the country information is in contradiction with the story told by the asylum seeker, the communication gets characteristics of epistemic violence as it excludes, negates, and/or nullifies the psychological thoughts, feelings, or experiential reality of the asylum seeker (see Sue et al. 2007) as most often the decision on the asylum claim in these cases is negative. The individual asylum seekers becomes disqualified as knower about his/her own situation and the interpretations done about a specific country become epistemic truths overriding individual experiences having severe consequences on the self-esteem of the person.

As described, the question in epistemic violence is whether or not there is a real possibility for a person to speak, express him-/herself and be heard. In particular, it is important to take into account how previous experiences and trauma affect the ability to communicate and/or remember things and events, and above all to express these things in a consistent and open manner. Elements, such as challenging experiences and the causes of traumas, are likely to have significant impacts on the safety aspects in the country of origin despite the fact that the individual is not necessarily able to tell them in the right way during the process. Moreover, as one of the participants explained: "In my home country I needed to fear militia. So, I learned very young to talk without telling much. I learned that I cannot trust. When I arrived, I should have told everything directly but I was too afraid to do so. I got negative [decision]. I noticed I need to trust and tell everything and I appealed. They said my story is not coherent and that I should have told everything directly".

Individuals of this research experience the consequences of (possible) epistemic violence e.g. distress, trauma and the loss of the direction of the life. As in various European countries immigration policies are tightened, these individuals are further negated as they are physically present in the societies but socially and legally negated and absent, alone with the psychological consequences of the past and the current situation. One participant told about his feelings: "I keep wondering what is wrong with me. Doesn't anybody like me or accept me as I am? I have no home country to go to or any family anywhere. Would it be better if I was dead? Then I think that no, not yet. I still can help someone else. I consciously think that so I can carry on".

\section{Concluding remarks}

The structure of the asylum interview is such that it creates vulnerabilities, threat of failure and being returned to the home country. Based on our analysis of the experiences, asylum seekers do not always feel they have been understood nor even heard. Sometimes there are smaller and bigger errors left in the documents from the interviews, which are difficult to retrieve afterwards. In some cases, there is lack in both, hermeneutical resources and desire to hear and understand the stories presented.

Epistemic violence is often characterised as personal violence (vs. structural). Even in the case presented here, there is a psychological and legal contact between interviewer and the asylum seeker; a subject and an object. However, the fact that epistemic violence occurs in an official hearing, transforms the violence into both; personal and structural.

Irregular migration is highly multidisciplinary phenomenon requiring a holistic evaluation and discussion about social policies gathering academics from various disciplines including (but not being limited to) psychology, geography, sociology and law. Epistemic violence needs to be avoided as much as possible in European immigration and social policies as it might, in fact, increase irregular migration. Additionally, most importantly, epistemic violence increases unnecessary torment and psychological distress for individual asylum seekers. Epistemic violence, as any other violence, has significant psychological effects through the negotiation of individual's self-esteem on a moment in which many experience to have lost the direction of the life. Consequently, we stress that the decision makers ought to acknowledge the possible side effects of the chosen social policies as those side effects, such as an increase in experienced epistemic violence, might have extensive impact on living conditions and the quality of life of people in the society. 


\section{References}

Aer, J. (2016). 'Ulkomaalaisoikeuden perusteet', Helsinki: Alma Talent.

Berenstain, N. (2016). Epistemic exploitation. Ergo, an Open Access Journal of Philosophy 3(22), 569-590.

Bergin, L. (2002). Testimony, epistemic difference, and privilege. Social Epistemology 16(3), 197-213.

Dotson, K. (2011). Tracking epistemic violence, tracking practices of silencing. Hypatia 26(2), 236-257.

Düvell, F. (2011). Paths into irregularity. The legal and political construction of irregular migration. European Journal of Migration and Law 13, 275-295.

Fricker, M. (2007). Epistemic injustice: Power and the Ethics of Knowing. Oxford: Oxford University Press.

Hornsby, J. (1995). Illocution and its significance in foundations of speech act theory - Disempowered speech. Philosophical topics 23(2), 127-147.

Jauhiainen, J. (2017). Turvapaikka Suomesta? Vuoden 2015 turvapaikanhakijat ja turvapaikkaprosessit Suomessa. Turku: University of Turku

Lehtikunnas, L. (2018). Should I stay or should I go - Irregularly somewhere in the middle. Master's thesis in international law. Turku: University of Turku

Migri (2018). Maahanmuuttoviraston selvitys sisäministerille turvapaikkapäätöksentekoon ja -menettelyyn liittyen. Helsinki: Finnish Immigration Service

Spivak, G. (1988). Can the Subaltern Speak? In C. Nelson \& L. Grossberg (Eds). Marxism and the Interpretation of Culture (pp. 271-317). Illinois: University of Illinois Press.

Sue, D. W., Capodilupo, C., Torino, G., Bucceri, J., Holder, A., Nadal, K. \& Esquilin, M. (2007). Racial microaggressions in everyday life: Implications for clinical practice. American Psychologist 62(4), 271-286.

Teo, T. (2008). From speculation to epistemological violence in psychology - A critical-hermeneutic reconstruction. Theory \& Psychology 18(1), 47-67.

Teo, T. (2010). What is epistemic violence in the empirical social sciences? Social and Personality Psychology Compass 4(5), 295-303.

Townley, C. (2006). Towards revaluation of ignorance. Hypatia 21(3), 37-55. 